\title{
Crianças em situação de rua: malabares da exclusão
}

Niños en situación de calle: malabarismos de la exclusión

Street children: jugglers of exclusion

\author{
Daniel Dall'Igna Ecker
}

Instituto de Psicologia, Universidade Federal do Rio Grande do Sul. Brasil

CAPES. Brasil

\begin{abstract}
Resumo: Este artigo discute os comportamentos de crianças em situação de rua, que frequentam semáforos, na cidade de Porto Alegre, Rio Grande do Sul, Brasil. Para o levantamento de dados foram realizadas 12 observações simples, com duração de 2 horas cada, objetivando coletar informações referentes aos comportamentos das crianças nos semáforos. Para análise do material, foi utilizada a estratégia de Análise de Conteúdo de Bardin. A partir dos resultados contrapôs-se os dados à teorias que apresentam análises sobre o desenvolvimento infantil e vulnerabilidade social. Constata-se que, sendo a inteligência algo que se constrói, também, social e economicamente, as crianças em situação de rua encontram-se em desvantagem. A vulnerabilização social, somada a uma exclusão que é também afetiva, produz nas crianças modos muito específicos de viver ligados à estratégias de sobrevivência na rua.
\end{abstract}

Palavras chave: crianças em situação de rua, comportamento, exclusão social, vulnerabilidade, desenvolvimento infantil

Resumen: Este artículo discute los comportamientos de los niños en las calles, que frecuentan los semáforos en la ciudad de Porto Alegre, Río Grande del Sur, Brasil. Para la recolección de datos se llevaron a cabo 12 observaciones simples, con una duración de 2 horas cada una, con el objetivo de recopilar información sobre el comportamiento de los niños en los semáforos. Para el análisis del material, se utilizó la estrategia de Bardin Análisis de Contenido. Los resultados de los datos fueron contrarrestados con las teorías que proporcionan un análisis del desarrollo del niño y la vulnerabilidad social. Se confirma que, en tanto la inteligencia es algo que se construye, también, social y económicamente, los niños en situación de calle están en desventaja. La vulnerabilización social, añadida a la exclusión que también es afectiva, produce en el niño formas de vida muy específicas en relación con las estrategias de supervivencia en la calle.

Palabras clave: niños en situación de calle, comportamiento, exclusión social, vulnerabilidad, desarrollo infantil

\begin{abstract}
This article discusses the behaviors of street children attending traffic lights in the city of Porto Alegre, Rio Grande do Sul, Brazil. The data collection consisted of 12 simple observations, each lasting 2 hours, aiming to collect information about the behavior of children at traffic lights. For material analysis, the Bardin Content Analysis strategy was used. From the results, the data were contrasted with theories that present analyzes about child development and social vulnerability. It is noticed that, since intelligence is something that is also built, socially and economically, street children are at a disadvantage. Social vulnerability, coupled with an exclusion that is also affective, produces in children very specific ways of living linked to strategies for survival on the street.
\end{abstract}

Key Words: street children, behavior, social exclusion, vulnerability, child development

Como citar este artigo:

Dall'Igna Ecker, D. (2017). Crianças em situação de rua: malabares da exclusão. Ciencias Psicológicas, 11(2), 139-148. doi: https://doi.org/10.22235/cp.v11i2.1483

Correspondência: Daniel Dall'Igna Ecker. Instituto de Psicologia, Universidade Federal do Rio Grande do Sul (UFRGS). Rua Ramiro Barcelos, 2600. Sala 136, Santa Cecília. CEP: 90035003 - Porto Alegre, RS - Brasil; e-mail: daniel.ecker@hotmail.com 


\section{Introdução}

Este artigo visa discutir os comportamentos de crianças em situação de rua, que frequentam semáforos, na cidade de Porto Alegre, Brasil. Para o debate, seguindo o método qualitativo, foram realizadas observações simples (Gil, 2010) com o objetivo de analisar aspectos referentes aos comportamentos das crianças nos semáforos. Visando trazer elementos à discussão, foi observado como a sociedade interage com as crianças. A partir dos resultados, colocou-se os dados obtidos em contraponto à teorias que apresentam análises sobre o desenvolvimento infantil e vulnerabilidade social.

Mesmo havendo uma série de políticas e intervenções, torna-se contrastante o fato de estarmos em pleno século vinte e um ainda existirem meninos e meninas em situação de rua que são excluídos de Direitos Sociais considerados básicos como educação, saúde, habitação, alimentação e transporte (Ferreira, 2011). Na ausência de direitos, os sujeitos acabam sendo relativamente forçados a desenvolverem outras estratégias de sobrevivência. No caso das crianças, por haver maior sensibilização diante delas, as mesmas são induzidas pelos pais ou conduzidas, por sua vulnerabilização social, a tornarem-se pedintes para que possam garantir o sustento da família.

A infância, segundo Papalia e Olds (2013), apesar de operar de diferentes formas de acordo com o contexto social, tem sido apontada como uma etapa da vida significativamente responsável pelo desenvolvimento físico, cognitivo e psicossocial das crianças. Se tiver acesso à escola, entre os 6 e 11 anos, os infantes passariam pelos chamados 'anos escolares', tornando-se a instituição escolar uma experiência central nessa fase de desenvolvimento. Apesar de os pais ainda terem grande importância, nesta etapa da vida os grupos em que convivem as crianças passam a se torna mais influentes que anteriormente.

No caso das crianças com privações socioeconômicas, a entrada na escola pode apresentar uma série de dificuldades. Como as avaliações são realizadas pelos professores levando em consideração habilidades cognitivas, que dependem de questões econômicas e sociais para serem desenvolvidas, não haveria um julgamento igualitário. As avaliações, as recompensas por comportamento e a confiabilidade em respeitar as obrigações, apesar das técnicas de ensino tentarem mensurar de forma justa, infelizmente acabam envolvendo e dando maior prestígio as crianças tidas como 'inteligentes' (Lidz, 1983).

Sendo a inteligência algo que se constrói, também, social e economicamente, as crianças em situação de rua podem ser colocadas em desvantagem quando inseridas em instituições escolares: ao menos que sejam feitos cuidados diferenciados, que levem em consideração os comportamentos adaptativos que elas desenvolveram as realidades da rua, as dificuldades podem se intensificar na escola. Nesse sentido, para formulação de políticas públicas, torna-se importante considerar elementos sobre os comportamentos de meninos e meninas em situação de rua, visando qualificar intervenções nos diferentes processos de suas vidas.

Para isto, o presente artigo apresenta um estudo de abordagem qualitativa sobre crianças em situação de rua, que frequentam semáforos. No texto, em um primeiro momento, serão apresentados aspectos teóricos referentes ao desenvolvimento infantil, o papel da família e da escola na educação, e questões sobre vulnerabilidade social e afeto na produção de infâncias das crianças em situação de rua. Em seguida, após detalhamento dos processos metodológicos, serão descritos os dados obtidos nas observações e discutido os mesmos contrapondo-os aos debates encontrados na literatura.

\section{Sob a ótica do desenvolvimento infantil}

Para Ferreira e Ries (2004), entre os 6 e 11 anos a criança passa pela fase de desenvolvimento chamada latência, onde as vivências sexuais são neutras e a libido (energia psicológica, gratificante e prazerosa) concentra-se nas aprendizagens, nas conquistas intelectuais e no desenvolvimento de amizades e grupos. É uma época em que surge a opinião nas crianças, na qual a linguagem serve não somente para se entender com os mais velhos, mas para a afirmação do eu. As palavras se transformam em um instrumento à disposição do interesse, sentimento e curiosidade, quando estes surgem na mente da criança (Coles, 1998). Nessa idade, elas estarão investindo seus interesses fora da família, criarão uma ênfase em encontrarem seus lugares nos grupos de colegas e formarão relacionamentos íntimos com amigos (Pansini \& Marin, 2011).

De acordo com Lewis e Wolkmar (1993), partes anteriores do desenvolvimento da criança nessa faixa etária parecem se organizar, de forma súbita, passando a funcionar de maneira fluente 
e integrada. Entretanto, todo esse conjunto de fenômenos vistos na infância, denominado latência, pode ser modificado por fatores culturais. Já Daniel e Shapiro (1996), ao revisarem de forma sistemática algumas áreas principais de dados sobre eventos biopsicológicos durante o processo evolutivo da infância, concluíram que a base do desenvolvimento durante esse período encontra-se mais em processos situados no interior do sistema nervoso central, desenvolvendo estratégias cognitivas cada vez mais sofisticadas e maduras. Considera-se então a maturação como uma descontinuidade significativa no desenvolvimento comportamental da infância. Assim, o termo latência, quando utilizado em seu sentido pleno, limita-se às mudanças intrapsíquicas que estão a ocorrer, especialmente quando diz respeito àquelas funções que auxiliam no aprimoramento dos controles internos como, por exemplo, os mecanismos de defesa, as capacidades crescentes de socialização, a formação de valores morais e as mudanças nos relacionamentos.

Conforme Papalia e Olds (2013), é na infância que as crianças, em média, duplicam seu peso corporal. Geralmente, neste período, elas têm um bom apetite e é necessária uma alimentação balanceada para que a criança se torne mais alerta e produtiva. A alimentação e os exercícios precisam ser estimulados para um saudável crescimento, mas cerca de 40 a $60 \%$ das crianças do mundo sofrem de subnutrição, pois vivem na miséria e são influenciadas, conseqüentemente, por outros tipos de privações ambientais que podem afetar não apenas o bem-estar físico, como também as capacidades cognitivas, o desenvolvimento social e emocional (Papalia \& Olds, 2013).

As crianças desenvolvem suas habilidades motoras como, por exemplo, a noção de lateralidade, principalmente nas atividades desenvolvidas nas escolas ou áreas recreativas. Como cita Pansini e Marin (2011), a entrada na escola é uma questão crucial neste período, pois as crianças irão para um lugar diferente de suas casas e terão que se encontrar nestes espaços. Nesse processo, os auto-conceitos das crianças, sistemas de valores e capacidades cognitivas, se modificam.

A maior parte das crianças desenvolve diversas habilidades que as ajudam a ter êxito na vida desde o momento em que ingressam na escola (Papalia \& Olds, 2013). Elas criam estratégias para aprender, criar, lembrar-se das coisas e resolverem problemas. Estas crianças tornam-se cada vez mais capazes de mostrar o conhecimento que possuem, de fazer e responder perguntas, de discutir idéias e de assumirem responsabilidades como, por exemplo, fazer o dever de casa. É nesta fase que seus processos cognitivos se aperfeiçoam, o tempo de processamento de informações diminui, a capacidade de atenção e a memória aumentam e a criança se torna mais apta no uso de estratégias mnemônicas, tais como os recursos externos, o ensaio, a organização e a elaboração.

Assim, seria durante os 6 e 11 anos que as crianças desenvolveriam o chamado sentimento de pertencer, que remeteria a sensação ou garantia em ser aceita por parte, ou integralmente, ao grupo e sociedade como um todo. Esse processo incluiria a identificação com a sociedade em que se vive e o compromisso com seus valores e éticas. Caso este sentimento não seja desenvolvido na criança, ela pode vir a desenvolver certa desconfiança dos pais e da sociedade de uma forma mais ampla, refletindo em ações de seu comportamento. Outro ponto importante referente ao desenvolvimento nesta idade, segundo Lidz (1983), seria o senso de responsabilidade que envolveria a disposição e capacidade em aprender e cumprir as regras sociais. As aprendizagens, referentes as regras sociais, são apontados pelo autor como muito centralizados a partir de ações dentro do cotidiano da escola e da família.

\section{Papel da escola e da família na educação}

Historicamente, a escola tem sido apresentada por sua função primordial de ensinar habilidades e conhecimentos as crianças. Esses ensinamentos, de forma geral, atuam de modo a preparar as crianças para a vida adulta. $\mathrm{Na}$ escola, aspectos cognitivos, psicológicos, biológicos e relacionais são trabalhados, de forma concomitante, desenvolvendo os alunos em suas diversas dimensões (Enguita,1989). A escola, assim, torna-se um grande órgão socializador, complementando as ações da família no que se refere a educação das crianças. Como a família, a sala de aula se torna um sistema social, mas pode desempenhar funções socializantes diferentes daquelas que os pais se preocupam (Pansini, \& Marin, 2011).

$\mathrm{Na}$ escola, a criança projeta seus interesses para outros adultos - como professores, chefes escoteiros, orientadores e outros - podendo superestimá-los. Todas essas projeções e fantasias vindas do menor fazem parte de um processo de 
crescente separação e autonomia (Ferreira, 1979). Além do mais, é na escola que a criança cria companheiros com quem brinca e se identifica. A escola também tem um papel indispensável quando se fala em aprendizagem e inteligência. Embora o desenvolvimento intelectual seja irregular e, também, socialmente criado, o Q.I. das crianças pode aumentar ou diminuir de 10 a 20 pontos durante os anos escolares. Além da habilidade inata da criança, a inteligência emocional é em parte baseada pelo grau de motivação, estabilidade emocional, estimulação, adequação do modelo e oportunidade os quais são muito trabalhados nas atividades escolares (Lewis, \& Wolkmar, 1993).

Segundo Papalia e Olds (2013), assim como a escola, os pais também terão forte influência na educação de seus filhos inclusive de forma indireta, por meio de suas maneiras de motivar as crianças à realizar atividades, incentivá-las ao envolvimento escolar e, principalmente, nas atitudes e crenças positivas que transmitem. No caso das crianças em situação de rua, Gregori (2000) discute que o ingresso precoce no trabalho causa uma substituição do tempo de infância (brincar, estudar e ser cuidado) por um 'tempo adulto', criando assim uma ruptura nos laços familiares. Como essas crianças não estarão acolhidas em suas famílias ou em suas comunidades, terão suas fronteiras de proteção rompidas, deparando-se assim com uma realidade extremamente dura que exige delas estratégias de sobrevivência.

A dificuldade é que enquanto as crianças de classes populares são desde cedo apresentadas à necessidade de garantir a própria sobrevivência, assumindo comportamentos adultos, as de classe alta vivem um longo período de 'latência social' onde são preparadas e protegidas, com métodos motivadores, para assumir quando adultos uma função anteriormente treinada. Assim, crianças que vem de lares onde sofrem privações por consequência de níveis socioeconômicos precários geralmente entram na escola com uma série de desvantagens no que se refere a vida em sociedade. Ao menos que sejam feitos cuidados diferenciados para elas, os obstáculos podem aumentar na escola. Como os professores avaliam e recompensam a criança por habilidades cognitivas, confiabilidade em respeitar as obrigações, bem como o comportamento em classe, apesar de seus esforços para avaliar igualitariamente, infelizmente acabam dando maior prestígio as crianças tidas como 'inteligentes' (Lidz, 1983).
Segundo Fagundes (1995) as escolas muitas vezes desenvolvem um ensino que não leva em consideração as diferentes realidades em que vivem as crianças, o que acaba por facilitar a evasão escolar. O afastamento do espaço da escola acaba por criar uma fragilidade no processo de desenvolvimento da criança, produzindo nela uma inversão de valores e uma lacuna criada pela falta do brincar que, inclusive, pode vir a acentuar vulnerabilidades. Contudo, para Paica-Rua (2002), não estar na escola e sim na rua, pedindo esmolas ou vendendo algo em semáforos, pode possibilitar a criança um ganho concreto, imediato. Através dele, tornar-se-ia possível auxiliar na subsistência e manutenção de sua família. De acordo com Gregori (2000), para alguns pais o trabalho precoce é algo positivo, pois ocuparia o tempo livre da criança e se tornaria uma prática educativa em termos de instituir responsabilidades como, por exemplo, de conhecimento sobre o uso do dinheiro e, até, como via de interação social.

\section{Vulnerabilidade social e relações de afeto}

$\mathrm{Na}$ literatura encontra-se uma série de grupos apontados como vulneráveis: idosos, crianças, portadores de deficiência, pessoas em situação de rua, mulheres, homossexuais, negros, dentre outros. Ser situado como sujeito vulnerável por vezes, opera como uma estratégia do governo para o desenvolvimento de políticas públicas. Contudo, mesmo recebendo atenção das políticas, seja pela garantia de benefícios ou serviços, esses acabam por não serem suficientes para garantir o mínimo de Direitos Sociais previstos em Constituição Federal do Brasil que garantam uma sobrevivência digna e alteração do quadro de pobreza e exclusão (Fagundes, 1995).

A pobreza, aqui definida aqui como carência de direitos, oportunidades e de esperanças complementa a exclusão social marcando a "falta de integração social que se manifesta através de regras que limitam o acesso de grupos particulares ou pessoas aos recursos ou aos direitos de cidadania" (Bento, $\&$ Carone, 2003, p.45). Entende-se que, em um grupo, para que haja exclusão, os excluídos devem ser considerados sem valor, indignos e, portanto, passíveis de serem prejudicados ou explorados. Exclusão é apontado como o descompromisso político dos que detêm o poder com o sofrimento daqueles em condições socioeconômicas precárias. Ela engloba grande parte da população mundial, 
tanto os que foram excluídos com a transformação do trabalho (desemprego e exigências maiores) quanto os que foram excluídos por estruturas econômicas que geram desigualdades absurdas na qualidade de vida dos diferentes grupos populacionais (Wanderley, 1997)

De acordo com Vargas (2002), os processos históricos evidenciam certa aliança entre o Estado e as elites brasileiras na construção de ideologias em torno da produção subjetiva dos diferentes grupos populacionais. Para López Autin (1980), ideologia é um conjunto de representações, crenças e ideias que, dentre suas diversas funções, moldam as simples preferências, atitudes, e até valores, que conduzem os comportamentos de determinados grupos sociais. Nisso, torna-se possível a construção de ideologias que, como cita Vargas (2002), fazem com que a sociedade tenha uma visão conflituosa e equivocada das crianças em situação de rua. Segundo o autor, medo e piedade caracterizariam os sentimentos paradoxais que marcam, como aponta Ferreira (1979), o sensacionalismo com que alguns casos sobre crianças em situação de rua têm sido reproduzidos na mídia. Nisso, acaba por se transformar crianças em situação de vulnerabilidade em 'crianças infratoras', mitos populares, que operam negativamente, disseminando sentimentos de insegurança e estigmatizando essa população.

Os processos de exclusão e estigmatização das classes menos favorecidas atuam de forma intensa e eficaz, não apenas colocando-as contra os demais grupos sociais, mas também para diferenciar as formas como são solucionados as dificuldades que cada um enfrenta. Assim, o que significa direito legítimo e ações de manutenção da qualidade de vida para as classes altas, transformam-se em repressão e imposição para as camadas populares tidas como marginalizadas. Estes mecanismos são tão eficientes que os próprios indivíduos, excluídos e estigmatizados, passam a admitir e justificar sua condição (Ferreira, 1979).

De acordo com Fagundes (1995), frente ao empobrecimento crianças e adolescentes, como estratégia de sobrevivência, procuram a rua para gerar renda. Muitas vezes, também são meninos e meninas que foram obrigados a sair de casa e abandonar a família, seja por falta de moradia, pela violência dos seus familiares contra eles ou por não terem o que comer. Conforme Vargas (2002) essas situações são complexas e envolvem vários fatores dispositivos. Dentre eles estão, por exemplo, a elitização de centros urbanos que acabam por vulnerabilizar ainda mais os sujeitos mais pobres. As crianças, nesse processo de vulnerabilização, tornam-se alvo das consequências das desigualdades sociais: seja pela não obtenção de acesso à Direitos Sociais básicos ou por sua inserção no mercado de trabalho informal.

Segundo Machado (2005), de modo geral, os menores trabalham devido a três fatores fundamentais: a exploração da pobreza, as expectativas da tradição familiar e a carência de acesso à educação, que acaba por resultar em tempos ociosos preenchidos com a vivência na rua. De acordo com o autor, as crianças submetidas ao trabalho podem ter essa função refletida em suas vidas de diferentes formas: desde uma perspectiva de beneficência, trazendo aquisição econômica e uma ocupação, sem interferir em sua educação, descanso ou lazer; até uma perspectiva de maleficência, que contribuirá negativamente para o desenvolvimento do menor, através de um trabalho que implique na exploração. Para o pesquisador, entre esses dois extremos, existiriam enorme variedades de atividades realizadas na rua que poderiam ou não interferir negativamente no desenvolvimento das crianças, sendo necessário avaliar cada situação em sua singularidade.

A rua, para Leczneisk (1995), produz-se não apenas como um espaço em que as crianças desenvolveriam estratégias de subsistência mas, além disso, torna-se-ia um espaço de interação social. Espaço para produção de vínculos de afeto, mostrados principalmente na relação com os amigos, transeuntes ou motoristas e passageiros que circulam nos diferentes meios de transporte e vias de pedestres. A interação social produzida quando as crianças encontram-se em situação de rua acaba sendo base de seus processos de socialização, pois muitos dos menores não teriam vínculos familiares consanguíneos e o grupo companheiro da rua acaba sendo cúmplice e servindo como uma forma de proteção. A briga entre as crianças de rua, quando ocorre, também é apontada pelo autor como, em grande parte, necessárias para se manterem relações afetivas saudáveis (Leczneisk, 1995).

De acordo com Papalia e Olds (2013), os vínculos de afeto seriam os principais responsáveis pelo desenvolvimento da auto-estima na criança, pois seriam através deles que os infantes desenvolveriam suas habilidades sociais, tendo no outro um reconhecimento importante para a manutenção das capacidades adquiridas. O processo de auto-conhecimento, diferenciação, 
espelhamento, semelhança, identificação, dentre outros, se produziriam na relação com o outro. $\mathrm{O}$ desenvolvimento cognitivo e emocional, centrais para sustentação da auto-estima, tendem a serem internalizados integralmente quando a criança coloca-se no mundo, em contato com outros, tornando assim as emoções aprendidas pela experiência diretamente relacionadas aos modos como a socialização das crianças se desenvolveu.

\section{Processos metodológicos}

Considerando aspectos apresentados anteriormente, o presente artigo resulta de um estudo $^{1}$, de método qualitativo, que visou discutir os comportamentos de crianças em situação de rua, que frequentam semáforos, na cidade de Porto Alegre, Brasil. Como questão de pesquisa, foram produzidas as seguintes perguntas: que modos de interação se produz entre meninos e meninas em situação de rua e a sociedade que circula seu entorno? Como pode-se relacionar a vivência dessas crianças com teorias sobre o desenvolvimento infantil e vulnerabilidade social?

Para o levantamento de dados foram realizadas 12 (doze) observações simples ${ }^{2}$ (Gil, 2010), com duração de 2 (duas) horas cada, com o objetivo de coletar informações referentes aos comportamentos das crianças em semáforos. Das 12 observações, 6 (seis) foram realizadas no turno da manhã e 6 (seis) no turno da tarde. Em relação ao sexo, não foi observado a presença de meninas no semáforo. No total das observações, encontrou-se 8 meninos diferentes, já que muitos deles retornavam ao mesmo semáforo em mais de um dia. Por inferência, acredita-se que todos os meninos tenham idade entre os 6 e 11 anos.

De acordo com Gil (2010), o método de observação simples possibilita a criação de hipóteses a respeito do problema pesquisado e torna possível obter dados sem relação direta ou interferência ao objeto de pesquisa. Visando trazer mais elementos à discussão, a observação atentou para o modo como a sociedade interage com as crianças nos semáforos. Para a análise dos dados foi utilizada a Análise de Conteúdo de Bardin (2011), sendo 1 Estudo realizado dentro da "Prática Interdisciplinar em Psicologia”. Aprovado pelo Faculdade de Psicologia (FAPSI) da PUCRS.

2 Com a presença de apenas um observador. Não havia roteiro prévio para a observação. Visando manter o anonimato, o espaço no qual o observador ficou localizado estava situado em uma estação de ônibus da via pública. a criação de inferências uma das estratégias para problematização dos materiais coletados. Para organização dos dados foram realizados diários de campo gravados em voz pelo pesquisador, concomitantemente as cenas visualizadas, e após transcritos.

Através dos resultados do estudo, colocou-se em discussão o material coletado em contraponto e articulado as teorias apresentadas inicialmente nesse texto. Essas, ao proporem análises sobre o desenvolvimento infantil e vulnerabilidade social, oferecem elementos importantes para reflexões sobre a produção de infâncias das crianças em situação de rua.

\section{Resultados e discussões}

\section{Sob a ótica do desenvolvimento infantil}

Conforme constatado no estudo, todas as crianças observadas aparentavam magreza corporal e precária prática alimentar, ou nenhuma, durante o período de permanência no semáforo. Se, como apontam Papalia e Olds (2013), seria na infância que as crianças duplicariam seu peso corporal, infere-se que a precária e não diversificada alimentação das crianças em situação de rua pode afetar negativamente em seu desenvolvimento físico. A única vez em que foi observado algum ato alimentar foi quando uma das crianças "pega uma de suas laranjas que estava sendo usada para fazer malabares e come- $a$ " (sic) ${ }^{3}$. Assim, acredita-se que as condições precárias com que vivem as crianças na mendicância em semáforos pode vir a exercer interferências negativas no seu bem estar e desenvolvimento físico.

Em compensação, referente as habilidades motoras apontadas por autores como principalmente desenvolvidas nas escolas ou áreas recreativas (Pansini, \& Marin, 2011), verificou-se que a prática dos malabares (com laranjas ou bastões de madeira) parecem ser úteis para o desenvolvimento das noções de lateralidade nas crianças. Contudo, apenas o uso de malabares pode ser apontado como um estímulo único e, portanto, limitado, reduzindo assim o espectro de estimulação das capacidades das crianças. A falta de diálogo (longo tempo no semáforo sem manter contato com outros) pode vir a interferir no modo como se estimula a

3 Para ilustração das observações será colocado entre aspas e em itálico fragmentos literais dos diários de campo gravados em voz e transcritos. 
atenção, memória, capacidade de criar, lembrar-se das coisas e resolver problemas, produzindo nas crianças capacidades cognitivas em um modo muito singular a operacionalidade das ruas.

A reflexão sobre o sentimento de pertencer, citado por Lidz (1983), emerge nas observações quando viu-se à criança sendo ignorada pelos motoristas. Muitos dos motoristas fecham as janelas, estacionam com distância do semáforo ou olham para o lado oposto em que está a criança quando essa se aproxima do veículo. Se questiona se esse modo de comportamento dos motoristas pode interferir na forma como a criança não se sente pertencente e aceita por parte deles, assim como não possibilita com que ela possa desenvolver sentimentos de identificação, inerentes ao desenvolvimento emocional dessa fase. Constata-se que a presença de outros menores pedintes, e alguns poucos adultos, funcionavam como certos modelos de comportamento as crianças que passavam a repetir trejeitos semelhantes a esses outros que também estavam no local.

Segundo Lidz (1983), o sentimento de pertencer é importante que seja produzido para que a criança não venha a desenvolver desconfiança dos seus semelhantes, familiares ou amigos, assim como da sociedade de uma forma mais ampla. Semelhante a esse sentimento, o autor também aponta o senso de responsabilidade como algo que permeia essa fase do desenvolvimento. Ele envolveria a disposição e capacidade de cumprir as regras sociais que, para ser produzido, seria importante que as crianças em situação de rua entrassem em contato com outros para, a partir de suas experiências e exemplos observados, internalizassem regras sobre a vida social.

Contudo, acredita-se que mesmo sendo excluída e ignorada, a experiência que vive a criança no semáforo possibilita sim aprendizagens sobre o funcionamento social. Mesmo que sejam aprendizagens a partir de um lugar de vulnerabilização e exclusão, a partir das observações infere-se que a energia investida pela criança em situação de rua serve como uma mola propulsora para que ela aprenda a como sobreviver no ambiente ao qual está exposta. Observou-se que as crianças passam a desenvolver comportamentos específicos que de alguma forma facilitam sua relação com a sociedade, motoristas e transeuntes. Muitas vezes os garotos observados mostravam agressividade, forma muito eficaz de intimidar os motoristas e fazer com que eles acabassem dando algo a eles, ou exprimiam uma face cativante, fazendo com que as pessoas se sentissem conquistadas, principalmente comovendo-se pelo fato de os pedintes serem crianças. Assim, as conquistas intelectuais acabam desenvolvendose nessas crianças em um modo muito específico ligado a estratégias de sobrevivência na rua.

A própria linguagem empregada por elas, segundo as observações, apresentavam uma elocução muito especifica da rua, marcando também nos infantes um lugar social que de certa forma identifica aqueles que pertencem as ruas e os que não pertencem. Como nesta idade há um investimento de interesses fora da família, acaba por serem os companheiros de rua, ou a falta deles, que a criança espelha seu desenvolvimento. Observou-se e infere-se que, muitas vezes, o aprendizado da criança parece operar, pelo fato de ela não ter exemplos, pela tentativa e erro: sua capacidade de socialização e valores morais vão sendo construídos cotidianamente de acordo com cada situação experienciada.

\section{Papel da escola e da família na educação}

Pelo observação, não obteve-se sinais de que as crianças no semáforo estariam frequentando a escola. O único menino visto com mochila, por exemplo, quando abriu a mochila não portava nenhum material didático a não ser os gravetos usados para os malabares e uma garrafa transparente que se inferiu ser alguma espécie de droga inalável pois, "após pegar a garrafa com o líquido transparente, o menino molha um pano e coloca na boca como se estivesse aspirando (...) repetindo essa ação diversas vezes". Assim, se não frequenta a escola, pode-se refletir que toda a função socializadora e estimuladora de habilidades que a escola pode ter (Pansini, \& Marin, 2011) acaba por ser perdida, sendo ocupado essa lacuna pela realidade em que os meninos vivem.

Referente a ideia de Lidz (1983), que a escola assume e complementa a função de família normalmente diferente das que os pais se preocupam, não tornou-se possível observar nos casos do estudo devido não haver informações suficientes para que seja afirmado que aqueles meninos frequentavam a escola. Contudo, infere-se que a falta de adultos, professores, orientadores, dentre outros que permeiam o contexto escolar, pode vir a limitar drasticamente o modo como a criança adquire conhecimentos, experimenta o mundo e 
desenvolve seus valores éticos e morais.

A necessidade da criança deste período, dos 6 aos 11 anos, com relação a ter companheiros com que possa brincar e se identificar, como supõe Papalia e Olds (2013), insurge nas observações quando visualiza-se a criança compartilhando seus objetos de mendicância com outras crianças, assim como quando ela compartilha o líquido inalante. Momentos de sorrisos e brincadeiras, muitas vezes solitárias, emergiram de forma limitada nas observações como, neste exemplo: "Ele pegou um pedaço de madeira e ficou batendo no cartaz de uma propaganda política. Sorri e parece se divertir ao mesmo tempo que seus movimentos parecem denunciar certo tédio ou inconformidade. É um sorriso estranho, que se intercala com um rosto sério, como se a brincadeira servisse para tentar fazê-lo sorrir ao mesmo tempo que seu corpo sente algo oposto a alegria".

Já em relação ao papel da família, não foi observado a presença de membros familiares, pai ou mãe, já que todas as crianças observadas chegavam e saiam do semáforo sozinhas ou com alguma criança próxima a sua idade (a qual talvez pudesse ser alguma espécie de familiar). Em apenas uma das observações foi visto um adulto por perto e inferiu-se que ele estava apenas trabalhando como vendedor de frutas e, em outra situação, viu-se meninas que distribuíam panfletos conversando e sorrindo para as crianças durante grande parte do contato entre eles. Assim, aponta-se para um limitado contato com adultos que, possivelmente, impossibilitaria aquilo que Papalia e Olds (2013) citam como necessário para a etapa da vida infantil e que seria função da família: adquirir atitudes e crenças positivas através do exemplo de adultos. Os motoristas e transeuntes, que grande parte ignoram e esboçam comportamentos repulsivos as crianças, talvez sejam os adultos que com mais frequência marcam presença no tempo em que as crianças ficam no semáforo.

Ao mesmo tempo, torna-se difícil contrapor uma teoria sobre o papel da família às especificidades apresentadas na vida de crianças em situação de rua. Afirmando a visão de Ferreira (1979), a dificuldade é que as crianças de classes populares são desde cedo apresentadas à necessidade de garantir a própria sobrevivência, necessidade essa que molda os comportamentos das crianças como pequenos adultos, organizando os membros familiares e suas funções de outra forma. A vul- nerabilização na qual são colocadas as crianças e suas famílias, por não haver a garantia de Direitos Sociais básicos, exige com que a criança trabalhe desde cedo: a venda de doces, flores ou o próprio exercício dos malabares e da mendicância parece ter uma utilidade econômica na vida da criança e, por inferência, acredita-se que essa possa ser uma forma importante de subsistência dela e de seus familiares.

\section{Vulnerabilidade social e relações de afeto}

A partir das observações infere-se que as crianças em situação de rua apresentam elementos significativos de vulnerabilização social. A presença na rua, talvez como reflexo da carência de direitos, roupas rasgadas, velhas, sujas, desproporcionais ("o chinelo que a criança usa deve ser quase duas vezes o tamanho de seu pé” (...) "tem algo marrom, talvez terra ou barro, em toda sua roupa, isso deve causar um desconforto significativo nela") alimentação precária, baixa ou nenhuma higiene, ausência de estímulos socialmente típicos a crianças de sua idade ("elas não brincam, pouco sorriem, e quanto mais ignoradas parece que mais sérias e desconfortáveis ficam, ali no semáforo, na frente de todos que pouco as olham"), a não presença de adultos e outros elementos marcam nos corpos da crianças a exclusão em meios a malabares que distraem.

Sobre o acesso à escola, ou em relação a outros benefícios e serviços públicos de garantia de direitos, citados por Fagundes (1995) como essenciais para um desenvolvimento pleno e saudável, não viu-se sua presença. A ausência de ações do Estado para garantia de Direitos Sociais básicos das crianças em situação de rua observadas marca uma inacessibilidade à bens materiais ao mesmo tempo em que a vulnerabilização potencializa-se por uma inacessibilidade à bens subjetivos. A exclusão social torna-se também uma exclusão subjetiva pelo modo como as crianças são tratadas: " a criança anda em direção a outro carro, oferece as balas, a pessoa não olha para ele".

Nisso, o uso de drogas inalantes parece ser uma estratégia para suportar uma realidade aparentemente muito desagradável. Como apontam Torres e Ecker (2017), cabe atentar para o sentido múltiplo, não apenas negativo, que o uso de substância química adquire neste contexto: "a criança está sendo ignorada por motoristas já fazem 30 
minutos, ela parece se incomodar e começa a inalar a substância novamente. Sob efeito do inalante, ela vai na janela de um carro que a ignora com o motorista olhando para o outro lado. A criança caminha em direção a frente desse mesmo carro e quase se deita em cima dele. É como se implorasse para ser olhada. O sinal abre, ela não sai da frente do carro e o motorista arranca. $O$ menino é empurrado, sai da frente do carro depois de ser arrastado por mais de um metro. Um transeunte grita: 'Ei quer morrer?'A criança volta para calçada parecendo anestesiada pela droga. Anestesiada, talvez ela não perceba todas essas cenas desagradáveis que vivência".

Possivelmente, como propõe Bento e Carone (2003), as marcas da exclusão refletem no modo como as crianças são tratadas pela sociedade. Ser 'mal vestida', pobre ou negra marca preconceitos que reforçam a ideia dos excluídos como sujeitos sem valor, indignos e, portanto, passíveis de serem prejudicados, explorados ou até arrastados pelos carros no semáforo. O sensacionalismo das mídias talvez seja outra estratégia de reforçar estereótipos e potencializar a visão errônea que há sobre crianças em situação de rua: aquela criança que seria vista como inocente se estivesse em outro contexto social, no semáforo é interpretada quase como um adulto criminoso.

Nesse contexto de vulnerabilidades e tensões, as relações de afeto parecem apresentar-se como uma possibilidade para produzir-se uma infância mais leve e alegre. Contudo, em 9 (nove) das 12 (doze) observações, no total das $2 \mathrm{~h}$ permanecidas no local, observou-se que as crianças tiveram contatos extremamente reduzidos com adultos e outras crianças. Em nenhum momento foi visto elas conversando ou interagindo de alguma forma, a não ser quando os carros compravam os doces ou davam algo a criança. Em uma das observações, um menino de, em média, 8 anos permaneceu sozinho sentado durante 45 minutos. Nesse caso, torna-se difícil colocar em discussão o desenvolvimento de habilidades propiciado pelo grupo, discutido por Papalia e Olds (2013), já que as crianças estavam em grande parte das observações sozinhas.

Os vendedores, as distribuidoras de panfletos e o jornaleiro viram figuras presentes na vida das crianças no semáforo: fizeram parte das observações e serviam de vínculos aos infantes, seja pela realização contato (piadas, interações físicas, auxílio para carregar os jornais, etc.) ou pela própria companhia que eles exercem a criança quando compartilham o mesmo local. Possivelmente, esses adultos sirvam como uma forma de proteção as crianças, pois em uma das observações viu-se o jornaleiro dar comida ao menino fazendo com que ele se sentisse cuidado e acolhido. Acolhimento, que talvez não seja ainda o suficiente para sustentar as fragilidades de ser vulnerabilizado social e afetivamente. Os malabares, que as crianças usam para distrair e alegrar os motoristas e transeuntes, parecem não alegrar à todos: "depois de 2 horas no semáforo o menino parece estar indo embora. Pega uma de suas laranjas dos malabares e joga com muita força contra o vidro da parada de ônibus. Pega a outra laranja e arremessa em direção a uma placa de transito. Os malabares não parecem representar algo feliz para ele".

\section{Considerações finais}

Através desse estudo, visou-se discutir os comportamentos de crianças em situação de rua, que frequentam semáforos, articulando os dados obtidos nas observações com teorias que apresentam análises sobre o desenvolvimento infantil e vulnerabilidade social. A partir dos materiais coletados, se observou e se inferiu uma série de reflexões sobre a produção de infâncias das crianças em situação de rua: marcadas por vulnerabilidades materiais, sociais e afetivas, suas vidas são marcadas por um cotidiano que apresenta condições de existência com estímulos limitados, e aparentemente desconfortáveis, quando comparado a vida daquelas crianças que possuem acesso aos seus Direitos Sociais básicos.

$O$ viver na rua, especificadamente na situação de semáforos como pedinte ou vendedor, produz na criança específicas relações sociais, valores culturais e produções de subjetividade. A solidão, a exclusão, o silêncio, a falta do olhar, aliado a precárias condições estruturais, desenvolve no infante comportamentos adaptativos para lidar com a uma realidade difícil. O comportamento de grande parte dos motoristas e pedestres, que cruzam de algum modo com essas crianças no cotidiano, seja dando dinheiro, interagindo ou ignorando-as, produzem nelas a marca de uma diferença: entre os que habitam a rua e os que apenas cruzam por ela. No habitar, vendedores, jornaleiros e panfletários tornam-se companhias e vínculos de afeto das crianças em meio a circulação de uma cidade 
que não inclui, ainda, todos e todas.

Por fim, visando qualificar a formulação de políticas públicas que intervenham na vida de crianças em situação de rua, sugere-se atentar para os elementos levantados no estudo: sendo a inteligência algo que se constrói, também, social e economicamente, as crianças em situação de rua encontram-se em desvantagem. Preocupa-se com a precária e não diversificada alimentação das crianças observadas, a falta de estímulos físicos e cognitivos diversificados e a possível consequência negativa que isso pode acarretar no seu desenvolvimento integral

A vulnerabilização social, somada a uma exclusão que é também afetiva, produz nas crianças modos muito específicos de viver ligados à estratégias de sobrevivência nas ruas. Esses aprendizados, por vezes constituídos pela tentativa e erro de uma criança solitária, remete a valores éticos e morais que vão sendo construídos desarticulados de uma vida social mais ampla. Os malabares, símbolos de alegria e distração daqueles que circulam em uma cidade, parecem representar a marca da exclusão nos corpos de quem os manipula, ou por eles são manipulados: as crianças pobres.

\section{Referências}

Bardin, L. (2011). Análise de conteúdo. São Paulo: Edições 70.

Bento, M. A. S., \& Carone, Iray. (2003). Psicologia social do racismo: estudos sobre branquitude e branqueamento no Brasil. $2^{\mathrm{a}}$ ed. Petrópolis: Vozes.

Coles, R. (1998). Inteligência Moral das Crianças. $2^{\mathrm{a}}$ ed. Rio de Janeiro; Editora Campus.

Daniel, J., \& Shapiro, J. (1996). Infant transitions: Home to center-based child care. Child and Youth Care Forum, 25(2), 111-123, 1996.

Enguita, M. F. (1989). A face oculta da escola. Porto Alegre; ARTMED.

Fagundes, H. S. (1995). O projeto multidisciplinar meninos e meninas de rua de São Leopoldo: análise do trabalho desenvolvido numa perspectiva de superação do assistencialismo e do preconceito para a construção da cidadania (Dissertação de Mestrado). Faculdade de Serviço Social da Pontifícia Universidade Católica do Rio Grande do Sul - PUCRS, Porto Alegre, RS, Brasil.
Ferreira, B. W., \& Ries, B. E. (2004). Psicologia e educação: desenvolvimento humano: adolescência e vida adulta. $2^{\mathrm{a}}$ ed. Porto Alegre: EDIPUCRS.

Ferreira, F. P. M. (2011). Crianças e Adolescentes em Situação de Rua e seus Macro Determinantes. Saúde e sociedade, 20(2), 338-349. doi: http://dx.doi.org/10.1590/S010412902011000200007

Ferreira, R. M. F. (1979). Meninos da rua: expectativas e valores de menores marginalizados em São Paulo. São Paulo: IBREX.

Gil, Antonio Carlos. (2010). Métodos e técnicas de pesquisa social. $7^{\mathrm{a}}$ ed. São Paulo: Atlas.

Gregori, M. F. (2000). Viração: experiências de meninos nas ruas. São Paulo: Companhia das Letras.

Leczneisk, L. (1995). Corpo, virilidade e gosto pelo desafio: a masculinidade entre guris de rua. Horizontes Antropológicos - Gênero 1(1), 95-111.

Lewis, M., \& Wolkmar, F. (1993). Aspectos Clínicos do Desenvolvimento na Infância e Adolescência. $3^{\mathrm{a}}$ ed. Porto Alegre. Artes Médicas.

Lidz, T. (1983). A pessoa: seu desenvolvimento durante o ciclo vital. Porto Alegre: Artes Médicas.

López Austin, A. (1980). Cuerpo Humano e Ideología. México: UNAM, Instituto de Investigaciones Antropológicas.

Machado, C. (2005). Crianças de Classes Populares e suas Representações sobre Infância, Família, Escola, e Raça/ Etnia. (Dissertação de Mestrado). Faculdade de Letras. Porto Alegre; Pontifícia Universidade Católica do Rio Grande do Sul/ BCE.

Pansini, F., \& Marin A. P. (2011). O ingresso de crianças de 6 anos no ensino fundamental: uma pesquisa em Rondônia. Educação e Pesquisa, 37(1), p.87-103. doi: http://dx.doi.org/10.1590/S1517-97022011000100006

Papalia, D. E., \& Olds, S. W. (2013). Desenvolvimento humano. $12^{\mathrm{a}}$ ed. Porto Alegre: Artmed.

Paica-Rua. (2002). Meninos e meninas em situação de rua: políticas integradas para a garantia de direitos. São Paulo: Cortez.

Torres, S., \& Ecker, D. (2017). Capacitação de profissionais sob a perspectiva da redução de danos: drogas, vamos pensar!. Revista Eletrônica Científica da UERGS, 3(1), 39-62.

Vargas, A. L. S. (2002). As sementes da marginalidade: uma análise histórica e bioecológica dos meninos de rua. Rio de Janeiro: Forense.

Wanderley, M. B. (1997). Desigualdade e Exclusão Social. São Paulo: EDUC. 